\title{
Investigation on the ohmic characteristic of $\mathrm{Ni} / \mathrm{Ti} / 4 \mathrm{H}-\mathrm{SiC}$
}

\author{
M. I. Idris', Z. A. F. M. Napiah², Marzaini Rashid ${ }^{3}$, M. N. Shah Zainudin', Siti Amaniah Mohd \\ Chachuli ${ }^{5}$, M. A. Azam 6 \\ 1,2,4,5Micro and Nano Electronic (MiNE), Centre for Telecommunication Research and Innovation (CeTRI), Fakulti \\ Kejuruteraan Elektronik dan Kejuruteraan Komputer, Universiti Teknikal Malaysia Melaka (UTeM), Hang Tuah Jaya, \\ 76100 Durian Tunggal, Melaka, Malaysia \\ ${ }^{3}$ School of Physics, Universiti Sains Malaysia (USM), 11800 USM, Penang, Malaysia \\ ${ }^{6}$ Fakulti Kejuruteraan Pembuatan, Universiti Teknikal Malaysia Melaka (UTeM), Hang Tuah Jaya, 76100 Durian \\ Tunggal, Melaka, Malaysia
}

\begin{tabular}{|c|c|}
\hline Article Info & ABSTRACT \\
\hline Article history: & \multirow{10}{*}{$\begin{array}{l}\text { Ohmic contact is important for silicon carbide (SiC) devices such as Schottky } \\
\text { diode, junction field effect transistor (JFET) and metal oxide transistor } \\
\text { (MOSFET). The effect of post metallization annealing (PMA) on the ohmic } \\
\text { characteristics of Ni/Ti/4H-SiC is investigated. The samples were annealed } \\
\text { under different ambients of high vacuum, forming gas and } \mathrm{N}_{2} \text { gas at } 1050^{\circ} \mathrm{C} \\
\text { for } 3 \text { minutes using rapid thermal process (RTP). Current-voltage }(I-V) \\
\text { measurements taken for different distances of a transmission line model } \\
\text { (TLM) structure have been utilized to extract the contact resistivity. The } \\
\text { correlation between surface roughness and resistivity has been investigated. It } \\
\text { was found that the involvement of nitrogen during the annealing process at } \\
1050^{\circ} \mathrm{C} \text { was ineffective to reduce the contact resistivity. The resistivity is } \\
\text { improved when the samples were annealed in forming gas (FG), (a mixture of } \\
\mathrm{H}_{2}+\mathrm{N}_{2} \text { ) environment, showing that the incorporation of } \mathrm{H}_{2} \text { gas during the } \\
\text { annealing process has produced a better result. On the other hand, high } \\
\text { vacuum PMA was found to be effective to improve the ohmic characteristic } \\
\text { with higher current level at lower voltage. Hence, the enhanced performance } \\
\text { observed in high vacuum annealing samples is beneficial to get ohmic contact } \\
\text { on } \mathrm{Ni} / \mathrm{Ti} / 4 \mathrm{H}-\mathrm{SiC} \text { for PMA process with a low thermal budget. }\end{array}$} \\
\hline Received Sep 7, 2020 & \\
\hline Revised Apr 26, 2021 & \\
\hline Accepted Aug 11, 2021 & \\
\hline Keywords: & \\
\hline $4 \mathrm{H}-\mathrm{SiC}$ & \\
\hline Contact resistivity & \\
\hline High-vacuum & \\
\hline Ohmic & \\
\hline PMA & \\
\hline
\end{tabular}

This is an open access article under the CC BY-SA license.

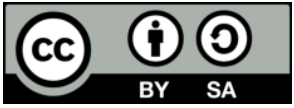

\section{Corresponding Author:}

Muhammad Idzdihar Idris

Micro and Nano Electronics (MiNE), Centre for Telecommunication Research and Innovation (CeTRI)

Faculty of Electronic and Computer Engineering (FKEKK), Universiti Teknikal Malaysia Melaka (UTeM)

Hang Tuah Jaya, 76100 Durian Tunggal, Melaka, Malaysia

Email: idzdihar@utem.edu.my

\section{INTRODUCTION}

In recent years, there has been an increasing demand for new semiconductor materials that can operate in extreme environments such as high temperature, high voltage and high radiation where the standard silicon electronics fail to function [1]. SiC is an interesting wide band gap material for electronic devices due to its excellent physical properties which involve a large bandgap $(3.26 \mathrm{eV})$, high breakdown electric field $\left(3 \times 10^{6} \mathrm{Vcm}^{-1}\right)$, high electron drift velocity $\left(2 \times 10^{7} \mathrm{~cm} \mathrm{~s}^{-1}\right)$, and good thermal conductivity $\left(4.9 \mathrm{~W} \mathrm{~cm}^{-1} \mathrm{~K}^{-1}\right)$ [2], [3]. In comparison to other wide band gap materials such as gallium nitride $(\mathrm{GaN})$ and aluminum nitride (AlN), SiC interestingly can be adopted to silicon technology production line without excessive cost. One of the advantages of $\mathrm{SiC}$ is the ability to be oxidized at elevated temperatures similar to silicon despite not having a good quality of the $\mathrm{SiC}_{\mathrm{SiO}}$ interface [4]-[6]. 
Wide variety of $4 \mathrm{H}-\mathrm{SiC}$ devices require low resistance, reproducible and stable ohmic contact [7]. One of the key issues that is limiting the performance of $\mathrm{SiC}$ devices is the challenge in forming ohmic contact on both $\mathrm{n}$ and p-type material because of high potential barrier at the interface between most metals and $\mathrm{SiC}$ that results in low current driving, low switching and increase of power dissipation. Numerous metals and annealing procesess were used to study the ohmic characteristic on SiC substrates. Nickel is the most commonly used metal for n-type $\mathrm{SiC}$ and $\mathrm{Al} / \mathrm{Ti}$ for p-type $\mathrm{SiC}$ [8], [9]. During annealing process $\left(>1000^{\circ} \mathrm{C}\right)$, nickel reacts with $\mathrm{SiC}$ substrates to form $\mathrm{Ni}$ silicides and result in a formation of graphite which deteriorate the electrical properties of the ohmic contact [10], [11]. Titanium nitride (TiN) is also a promising material for the formation of ohmic contact on $4 \mathrm{H}-\mathrm{SiC}$. It was reported that the TiN (111) lattice planes are parallel to (0001) SiC oriented substrate. The calculation of first-principle has shown that the Schottky barrier height $(\mathrm{SBH})$ is as low as $0.03 \mathrm{eV}$ where the bandgap almost disappears at the interface [12].

Tungsten is one of the hardest material and has an outstanding properties of high melting point compared to other metal. It is used as a contact material to improve the thermal stability because of its capability to prevent an undesirable influence of carbon. Low specific contact resistance, $\rho_{\mathrm{c}}$ can be achieved with high temperature annealing. One of the approach to reduce the $\rho_{c}$ is to use W/Ni bilayeron n-type $4 \mathrm{H}-$ $\mathrm{SiC}$. It was reported that by adding the $\mathrm{W}$ layer, it will reduce the voids at the interface, thus makes the surface smooth. One of the advantages of having W layer is wore bonding process can be achieved easily [13]. Rapid thermal annealing is commonly used for the formation of ohmic contact on $4 \mathrm{H}-\mathrm{SiC}$. Due to high thermal budget, laser annealing has been proposed as an annealing method for the silicidation of the contact. Low $\rho_{\mathrm{c}}$ in the order of $10^{-5} \Omega \mathrm{cm}^{2}$ was reported using a laser with a power of $0.9 \mathrm{~J} / \mathrm{cm}^{2}$ [14]. In this work, we investigated the effect of the PMA with different ambient which are high vacuum, forming gas and nitrogen gas. The ohmic characteristics of $\mathrm{Ni} / \mathrm{Ti} / \mathrm{n}$-type $4 \mathrm{H}-\mathrm{SiC}$ were measured Keithley 4200-SCS semiconductor parameter analyzer. Then, the individual contacts were analyzed using AFM and Raman spectroscopy.

\section{EXPERIMENTAL WORK}

A test structure was prepared to measure the contact resistivity as shown in Figure 1. On the top of the rectangular mesa structure, multiple rectangular contacts were formed with varying spacing. The resistance between two terminals is measured with four probes, two for current, two for voltage and the measured resistance is plotted against the contact spacing. The measured resistance, $R_{T}$ consist of the two contact resistances and the resistance of the semiconductor can be expressed as,
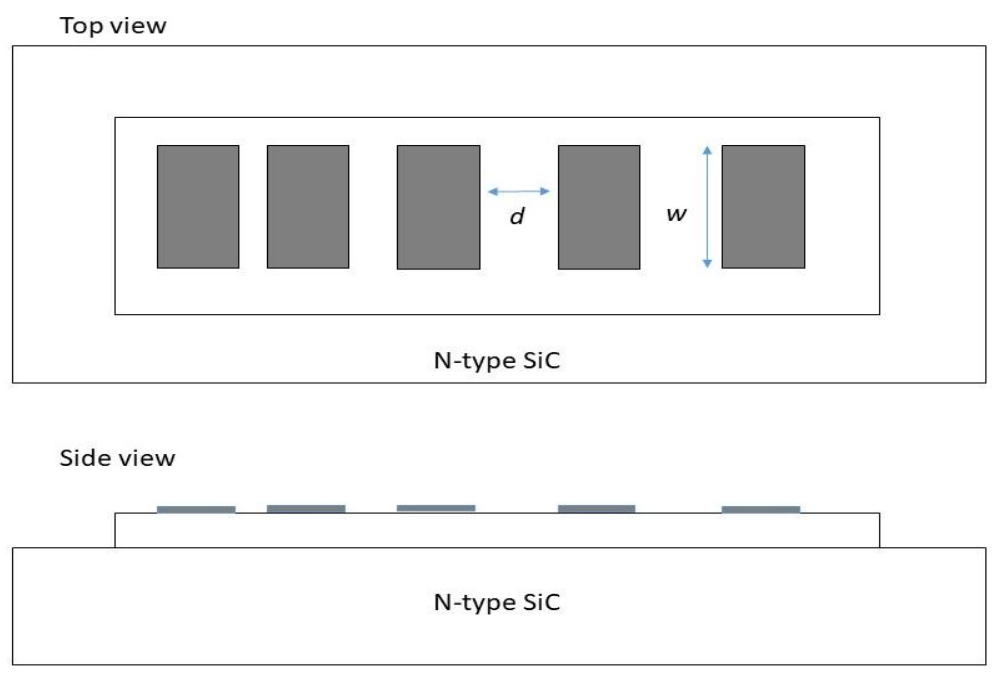

Figure 1. Test structure used to measure accurate contact resistivity using the linear transfer length method (TLM) [15]-[17]

$$
R_{T}=R_{s h} \frac{d}{w}+2 R_{C}
$$

where $R_{s h}$ is the sheet resistance of the semiconductor, $d$ is the spacing between contacts, $w$ is the contact width and $R_{C}$ is the contact resistance. The contact resistivity is given by

$$
\rho_{C}=R_{C} L_{T} w
$$


$\mathrm{N}$-type $4 \mathrm{H}$-SiC substrate with concentration of $1 \times 10^{18} \mathrm{~cm}^{-3}$ were used in this experiment. First, the samples were cleaned using solvents, then treated with piranha solution prior to standard RCA. Titanium (5 $\mathrm{nm}) /$ nickel $(100 \mathrm{~nm})$ were deposited on the rectangular mesa structure and annealed at $1050^{\circ} \mathrm{C}$ for 3 minutes in different ambients using RTP. The annealing processes for the formation of ohmic contact are described in Table 1.

Table 1. Description of the annealing processes used in the formation of ohmic contact

\begin{tabular}{cccc}
\hline Sample & Metal & Annealing temperature & Ambient \\
\hline 1 & $\mathrm{Ni} / \mathrm{Ti} / \mathrm{SiC}$ & $1050^{\circ} \mathrm{C}$ & High vacuum $\left(1 \times 10^{-5} \mathrm{mbar}\right)$ \\
2 & $\mathrm{Ni} / \mathrm{Ti} / \mathrm{SiC}$ & $1050^{\circ} \mathrm{C}$ & Forming gas \\
3 & $\mathrm{Ni} / \mathrm{Ti} / \mathrm{SiC}$ & $1050^{\circ} \mathrm{C}$ & $\mathrm{N}_{2}$ gas \\
\hline
\end{tabular}

\section{RESULTS AND DISCUSSION}

\subsection{Current-voltage $(I-V)$ measurement}

$I$ - $V$ measurements were performed by Keithley 4200 semiconductor characterization system to obtain the specific contact resistance of the samples. The data in Figure 2 (a), (b) and (c) show the $I-V$ characteristics with different contact spacing for $\mathrm{Ni} / \mathrm{Ti}$ n-type $4 \mathrm{H}-\mathrm{SiC}$ for samples annealed with different ambients. All samples show the typical linear $I-V$ curve indicating the formation of ohmic contact. The contact resistivity of all samples were extracted using linear transfer length method as shown in (1) and (2). Sample 1 exhibits the lowest value with about $1 \times 10^{-4} \Omega \mathrm{cm}^{2}$, then followed by sample 2 with $7 \times 10^{-4} \Omega \mathrm{cm}^{2}$ and sample 3 with $1 \times 10^{-3} \Omega \mathrm{cm}^{2}$. It can be seen that sample annealed in high vaccum shows better ohmic behaviour than samples annealed in Forming gas and $\mathrm{N}_{2}$ gas.



(a)

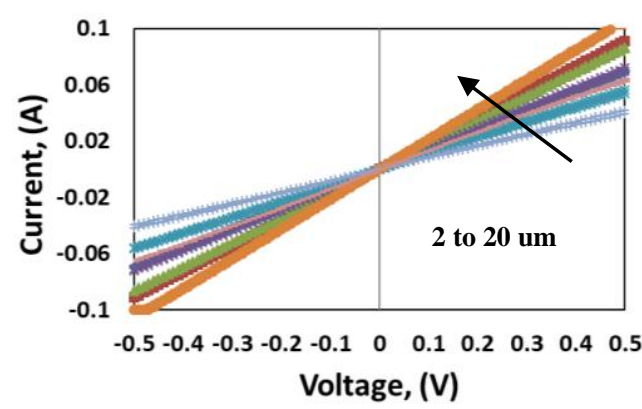

(b)

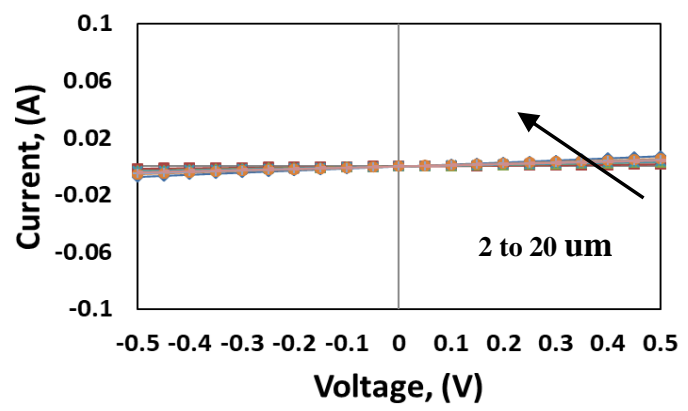

(c)

Figure 2. I-V characteristics of the $\mathrm{Ni} / \mathrm{Ti} / \mathrm{n}$-type $\mathrm{SiC}$ annealed at $1050^{\circ} \mathrm{C}$ for 3 minutes for, (a) sample 1 , (b) sample 2, (c) sample 3

\subsection{Surface morphology}

The surface morphology of Ni/Ti contacts were studied by atomic force microscope (AFM) after the annealing process. Two surface roughness parameters of $R_{a}$, roughness average and $R_{q}$ RMS roughness were used for this analysis. $\mathrm{R}_{\mathrm{a}}$ is the arithmetic average of the absolute values of the surface height deviations 
measured from the mean plane. $\mathrm{R}_{\mathrm{q}}$ is the root mean square average of height deviation taken from the mean image data plane. Sample 1 in Figure 3 has a smooth surface with $R_{a}=4.88 \mathrm{~nm}$ and $R_{q}=6.55 \mathrm{~nm}$. Hydrogen atoms in Forming gas annealing has resulted in a rough surface to Sample 2 with $R_{a}=52.8 \mathrm{~nm}$ and $R_{q}=68.4$ $\mathrm{nm}$. Sample 3 has better surface quality in comparison to Sample 2 due to the absence $\mathrm{H}$ atom in $\mathrm{N}_{2}$ gas. This experiment proved that the surface morphology of contact depends on the annealing ambient and also high surface roughness could also contribute to the observed decrease in contact resistance. The surface quality is better when the process of annealing is in high vacuum. From the observation of contact structures by means of optical microscopy, the colour of contact for Sample 2 and 3 changes to black and orange respectively, whereas sample 1 reveals almost no colour change during HV annealing. This results indicates that metal $\mathrm{Ni} / \mathrm{Ti}$ on Samples 2 and 3 have changed its properties due to the interaction of $\mathrm{SiC}$ and $\mathrm{Ni} / \mathrm{Ti}$ at $1050^{\circ} \mathrm{C}$. This a clear evidence that the character of $\mathrm{Ni} / \mathrm{Ti} / \mathrm{n}$-type $\mathrm{SiC}$ interaction is different under different annealing ambient [18].

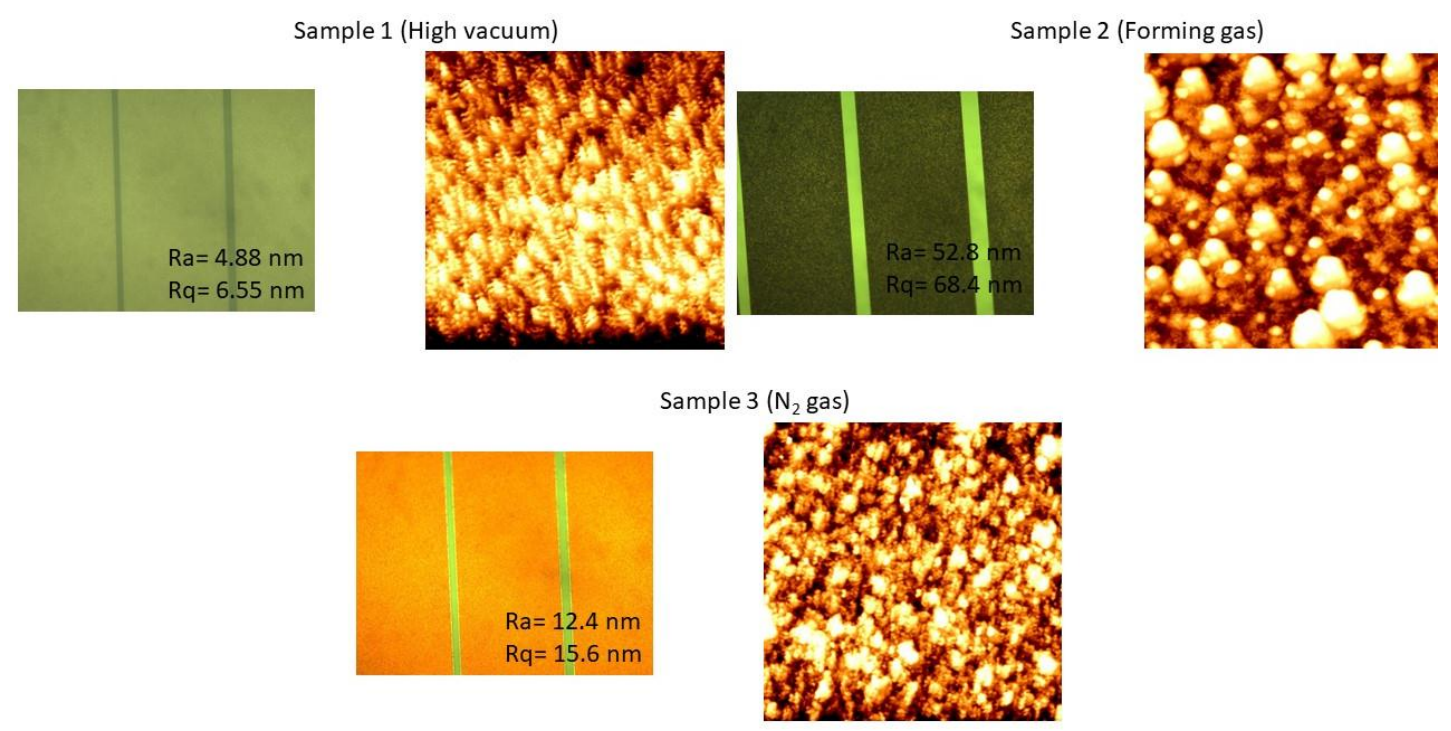

Figure 3. Microscope and AFM images of Ni/Ti contact on n-type SiC after PMA process

\subsection{Raman study}

It was reported that Raman scattering is useful to study the interface properties between metal and semiconductor [19]. Raman scattering is a nondestructive method and since SiC is highly transparent for visible lasers, laser probing of the metal/SiC is possible. From Raman spectra, information about the structure and the composition of the samples can be given by the phonon frequencies. The information about the doping level can be obtained from the frequency of couple plasmon LO phonon modes. In this work, $\mathrm{Ni} / \mathrm{Ti} / \mathrm{SiC}$ interface was investigated by Raman scattering. Figure 4 show the Raman spectra observed from both the Ni layer. The spectra shows that nickel silicides were formed by annealing [20].

Raman scattering was observed at room temperature using the $514.5 \mathrm{~nm}$ line of an Ar ion laser for excitation. The observation was done in the backscattering geometry as described below using a Raman microscope with an objective lens of $100 \mathrm{X}$ magnification. The scattered light was collected by the same lens, fed to a double monochromator of focal length $85 \mathrm{~cm}$, and the Raman spectra were observed by a liquid-nitrogen cooled charge-coupled device camera.

Figure 4 (a) and (b) show the Raman spectra observed for samples with different PMA conditions in a range of 0 to 300 and 1000 to 2500 Raman shift $\left(\mathrm{cm}^{-1}\right)$ respectively. According to the reported Raman data [19], [21], signals that are ascribed to three kind of nickel silicides are; (1) $\mathrm{Ni}_{2} \mathrm{Si}\left(100\right.$ and $\left.140 \mathrm{~cm}^{-1}\right),(2) \mathrm{NiSi}$ $\left(190\right.$ and $\left.215 \mathrm{~cm}^{-1}\right)$ and $\mathrm{NiSi} 2\left(260,310\right.$ and $\left.370 \mathrm{~cm}^{-1}\right)$. For samples annealed in $\mathrm{FG}$ and $\mathrm{N}_{2}$ ambient, the peaks for $\mathrm{Ni}_{2} \mathrm{~S}$ at 100 and $140 \mathrm{~cm}^{-1}$ are very significant in comparison to peaks for $\mathrm{NiSi}$ and $\mathrm{NiSi}_{2}$. Only sample annealed in $\mathrm{N}_{2}$ shows peaks at range between 190 and $215 \mathrm{~cm}^{-1}$ ).

Due to the lack of knowledge of the Raman scattering efficiency of respective species, the discussion is focusing on the dominant species of $\mathrm{Ni}_{2} \mathrm{Si}$. The formation of nickel silicide $\left(\mathrm{Ni}_{2} \mathrm{Si}\right)$ show interesting variation with the annealing ambient. The data in Figure 4(a) show that the intensity of samples annealed in $\mathrm{N}_{2}$ has the highest signal intensity, then followed by the samples annealed in FG. On the contrary, the signal for samples annealed in high vacuum (sample 1) are not apparent in comparison to both 
sample ( $\mathrm{FG}$ and $\mathrm{N}_{2}$ ) even annealed at high temperature of $1050^{\circ} \mathrm{C}$. This proves that $\mathrm{Ni}$ and $\mathrm{Si}$ did not react in high vacuum even at $1050^{\circ} \mathrm{C}$. With this result in mind, Figure 4 (a) and (b) clearly show that formation of nickel silicides at the interface region is not the key factor for ohmic contact. These results are consistent with results from other researchers [1], [22].

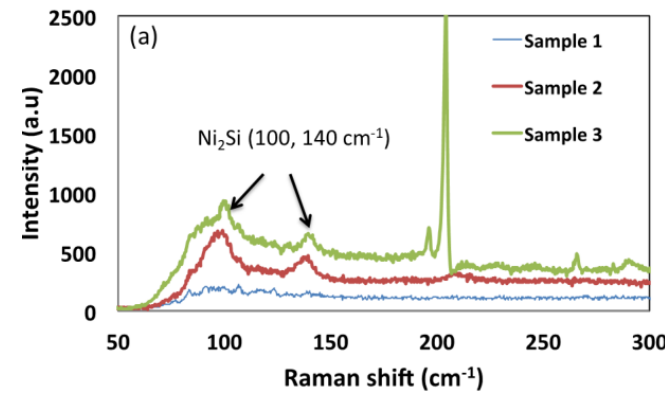

(a)

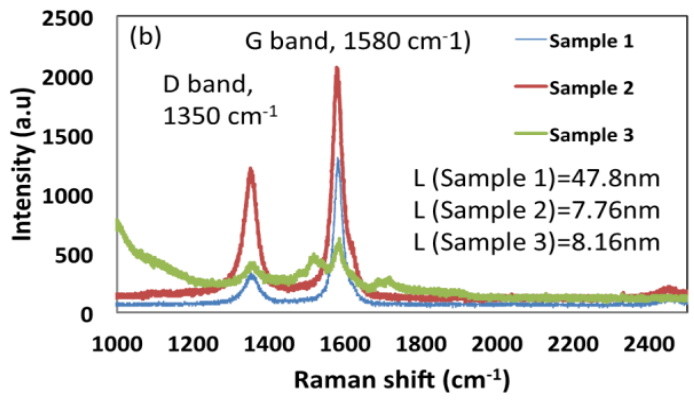

(b)

Figure 4. Raman spectra observed for samples with different PMA conditions; (a) Raman spectra observed from Ni/Ti side, (b) graphite signals observed for sample 1, 2 and 3 in Figure 3. Microscope and AFM images of $\mathrm{Ni} / \mathrm{Ti}$ contact on $\mathrm{n}$-type $\mathrm{SiC}$ after PMA process

It was reported that decomposition of $\mathrm{SiC}$ which starts at $500^{\circ} \mathrm{C}$ resulted in a distribution of carbon atoms on the surface of electrode layer [23]. Here we observe Raman spectra in higher frequency region, 1000 to $2000 \mathrm{~cm}^{-1}$. Figure 4 (b) shows the typical two peaks observed at 1350 and $1580 \mathrm{~cm}^{-1}$ respectively, called $D$ (disorder), and $G$ (graphitics) bands (characteristics features of graphite clusters or defective graphite crystals) [24], [25]. Carbon atoms, which did not react with $\mathrm{Ni}$, may form a carbon rich region at the interface, in the layer or at the surface in the form of graphite clusters or defective graphite crystals. In the case of cluster, the size, $L(\mathrm{~nm})$ can be estimated by the relative intensity of $D$ to $G$ bands as:

$$
L=4.4\left(\frac{I_{G}}{I d}\right)
$$

We obtain the size $L=47.8 \mathrm{~nm}, L=7.76 \mathrm{~nm}$ and $L=8.16 \mathrm{~nm}$ for sample 1 , sample 2 and sample 3 respectively. From the result, nanometer size carbon cluster were distributed throughout the nickel layer where sample 1 yielded the largest cluster size.

The ohmic behavior may be explained by two possible hypotheses: (1) the formation of graphite during annealing process [26] or (2) the interaction at the interface of $\mathrm{Ni} / \mathrm{Ti}$ and silicon carbide [27]. However, from the Raman analysis, there is no correlation between specific contact resistance and average size of carbon crystallites, $L$. Additionally, it can be concluded that it is not the interaction of Ni/Ti during annealing process that influences the contacts. Hence, the two hypotheses can be ruled out; which strongly suggests that the gas/ambient (vacuum, $\mathrm{FG}$ or $\mathrm{N}_{2}$ ) also play a big role in determining the quality of ohmic contact [17], [28].

\section{CONCLUSION}

The effect of PMA on the ohmic characteristics of Ni/Ti/ 4H-SiC in different environment was investigated. PMA in high vacuum is a suitable route to the realization of low resistivity ohmic contact without the usage of gas. PMA of $\mathrm{Ni} / \mathrm{Ti} / \mathrm{n}$-type $\mathrm{SiC}$ in high vacuum has shown good result to obtain better characteristics of ohmic contact. Analysis for Raman scattering clearly show that formation of nickel silicide has no relation with the formation of ohmic contact. Distribution of nanometer size carbon cluster on the contact was also verified. The finding results suggest that PMA of $\mathrm{Ni} / \mathrm{Ti} / \mathrm{n}$-type $\mathrm{SiC}$ in high vacuum is the key to improving the ohmic characteristics of $\mathrm{SiC}$ devices.

\section{ACKNOWLEDGEMENTS}

The authors would like to thank Universiti Teknikal Malaysia Melaka (UTeM) for sponsoring this paper under Project No. RACER/2019/FKEKK-CETRI/F00405. 


\section{REFERENCES}

[1] I. P. Nikitina, K. V. Vassilevski, N. G. Wright, A. B. Horsfall, A. G. O'Neill, and C. M. Johnson, "Formation and role of graphite and nickel silicide in nickel based ohmic contacts to n-type silicon carbide," Journal of Applied Physics, vol. 97, no. 8, p. 083709, 2005, doi: 10.1063/1.1872200.

[2] N. G. Wright, A. B. Horsfall, and K. Vassilevski, "Prospects for SiC electronics and sensors," Materials Today, vol. 11, no. 1-2, pp. 16-21, 2008, doi: 10.1016/S1369-7021(07)70348-6.

[3] L. C. Yu, G. T. Dunne, K. S. Matocha, K. P. Cheung, J. S. Suehle and K. Sheng, "Reliability Issues of SiC MOSFETs: A Technology for High-Temperature Environments," in IEEE Transactions on Device and Materials Reliability, vol. 10, no. 4, pp. 418-426, Dec. 2010, doi: 10.1109/TDMR.2010.2077295.

[4] J. N. Shenoy, G. L. Chindalore, M. R. Melloch, J. A. Cooper, J. W. Palmour, and K. G. Irvine, "Characterization and optimization of the $\mathrm{SiO} 2 / \mathrm{SiC}$ metal-oxide semiconductor interface," Journal of Electronic Materials, vol. 24, no. 4, pp. 303-309, 1995, doi: 10.1007/BF02659691.

[5] S. M. Thomas et al., "Enhanced Field Effect Mobility on $4 \mathrm{H}-\mathrm{SiC}$ by Oxidation at $1500^{\circ} \mathrm{C}$," in IEEE Journal of the Electron Devices Society, vol. 2, no. 5, pp. 114-117, Sept. 2014, doi: 10.1109/JEDS.2014.2330737.

[6] M. I. Idris, M. H. Weng, H.-K. Chan, A. E. Murphy, D. T. Clark, R. A. R. Young, E. P. Ramsay, N. G. Wright, and A. B. Horsfall, "Instability of phosphorous doped $\mathrm{SiO} 2$ in $4 \mathrm{H}-\mathrm{SiC}$ MOS capacitors at high temperatures," Journal of Applied Physics, vol. 120, no. 21, pp. 214902, 2016, doi: 10.1063/1.4969050.

[7] A. V. Kuchuk, M. Guziewicz, R. Ratajczak, M. Wzorek, V. P. Kladko, and A. Piotrowska, "Long-term stability of Ni-silicide ohmic contact to n-type 4H-SiC," Microelectronic Engineering, vol. 85, no. 10, pp. 2142-2145, 2008, doi: 10.1016/j.mee.2008.04.011.

[8] T. Ohyanagi, Y. Onose, and A. Watanabe, "TiNi bilayer Ohmic contact on 4H-SiC," Journal of Vacuum Science \& Technology B Microelectronics and Nanometer Structures, vol. 26, no. 4, p. 1359, 2008, doi: 10.1116/1.2949116.

[9] M. Siad, M. Abdesselam, N. Souami, and A. C. Chami, "Structural characterization of Ni and Ni/Ti ohmic contact on n-type 4H-SiC," Applied Surface Science, vol. 257, no. 24, pp. 10737-10742, 2011, doi: 10.1016/j.apsusc.2011.07.089.

[10] I. P. Nikitina, et al., "Structural pattern formation in titanium-nickel contacts on silicon carbide following hightemperature annealing," Semiconductor Science and Technology, vol. 21, no. 7, pp. 898-905, 2006, doi: $10.1088 / 0268-1242 / 21 / 7 / 013$.

[11] M.I. Idris, N.G. Wright, and A. B. Horsfall, "Effect of Post Oxide Annealing on the Electrical and Interface 4HSiC/Al2O3 MOS Capacitors," Materials Science Forum, vol. 924, pp. 486-489, 2018, doi: 10.4028/www.scientific.net/MSF.924.486.

[12] Z. Wang, X. Wang, W. Liu, X. Ji, and C. Wang, "Ohmic contact formation mechanisms of TiN film on 4H-SiC," Ceramics International, vol. 46, no. 6, pp. 7142-7148, 2019, doi: 10.1016/j.ceramint.2019.11.206.

[13] S. Jiang, X. Li and Z. Chen, "Role of W in W/Ni Bilayer Ohmic Contact to n-Type 4H-SiC From the Perspective of Device Applications," in IEEE Transactions on Electron Devices, vol. 65, no. 2, pp. 641-647, Feb. 2018, doi: 10.1109/TED.2017.2784098.

[14] M. De Silva, T. Kawasaki, T. Miyazaki, T. Koganezawa, S. Yasuno, and S. I. Kuroki, "Formation of epitaxial TiSi-C Ohmic contact on 4H-SiC C face using pulsed-laser annealing," Applied Physics Letters, vol. 110, no. 25, p. 252108, 2017, doi: 10.1063/1.4987136.

[15] H. Vang, et al., "Ni-Al ohmic contact to p-type 4H-SiC," Superlattices and Microstructures, vol. 40, no. 4-6, pp. 626-631, 2006, doi: 10.1016/j.spmi.2006.08.004.

[16] D. K. Schroder, "Semiconductor Material and Device Characterization: Third Edition," Wiley Online Library, John Wiley \& Sons, 2006, doi: 10.1063/1.2810086.

[17] S. Lee, "Processing and Characterization of Silicon Carbide ( $6 \mathrm{H}-$ and $4 \mathrm{H}-\mathrm{SiC}$ ) Contacts for High Power and High Temperature Device Applications," Materials Science, p. 106, 2002.

[18] F. Giannazzo, F. Roccaforte, V. Raineri and D. Salinas, "Effect of Thermal Annealing on the Electrically Active Profiles and Surface Roughness in Multiple Al Implanted 4H-SiC," 2007 15th International Conference on Advanced Thermal Processing of Semiconductors, 2007, pp. 71-73, doi: 10.1109/RTP.2007.4383821.

[19] E. Kurimoto, H. Harima, T. Toda, M. Sawada, M. Iwami, and S. Nakashima, "Raman study on the Ni/SiC interface reaction," Journal of Applied Physics, vol. 91, no. 12, pp. 10215-10217, 2002, doi: 10.1063/1.1473226.

[20] M. R. Jennings et al., "Analysis of Al/Ti, Al/Ni multiple and triple layer contacts to p-type 4H-SiC," Solid-State Electronics, vol. 51, no. 5, pp. 797-801, 2007, doi: 10.1016/j.sse.2007.02.037.

[21] S. Cichoň, P. MacHáč, B. Barda, V. MacHovič, and P. Slepička, "Raman study of Ni and Ni silicide contacts on 4H- and 6H-SiC," Thin Solid Films, vol. 520, no. 13, pp. 4378-4388, 2012, doi: 10.1016/j.tsf.2012.02.008.

[22] K. Smedfors, "Ohmic Contacts for High Temperature Integrated Circuits in Silicon Carbide," in Doctoral dissertation, KTH Royal Institute of Technology, 2014.

[23] S. C. Chang, S. J. Wang, K. M. Uang, and B. W. Liou, "Investigation of Au/Ti/Al ohmic contact to N-type 4HSiC," Solid-State Electronics, vol. 49, no. 12, pp. 1937-1941, 2005, doi: 10.1016/j.sse.2005.08.013.

[24] B. Barda, et al., "Origin of ohmic behavior in Ni, Ni2Si and Pd contacts on n-type SiC," Applied Surface Science, vol. 257, no. 2, pp. 414-422, 2010, doi: 10.1016/j.apsusc.2010.07.003.

[25] M. Siad, M. Abdesslam, and A. C. Chami, "Role of carbon in the formation of ohmic contact in Ni/4HSiC and Ni/Ti/4HSiC," Applied Surface Science, vol. 258, no. 18, pp. 6819-6822, 2012, doi: 10.1016/j.apsusc.2012.03.108.

[26] Q. Song, Y. Zhang, Y. Zhang, and X. Tang, "Investigation of surface morphology and ion activation of aluminium implanted 4H-SiC," Science China Technological Sciences, vol. 55, no. 12, pp. 1-4, 2012, doi: 10.1007/s11431$012-4827-4$

[27] F. Roccaforte, F. La Via, and V. Raineri, "Ohmic Contacts To SiC," International Journal of High Speed 
Electronics and Systems, vol. 15, no. 04, pp. 781-820, 2006, doi: 10.1142/s0129156405003429.

[28] R. Konishi, R. Yasukochi, O. Nakatsuka, Y. Koide, M. Moriyama, M. Murakami, "Development of Ni/Al and $\mathrm{Ni} / \mathrm{Ti} / \mathrm{Al}$ ohmic contact materials for p-type 4H-SiC," Materials Science and Engineering: B, vol. 98, no.3, pp. 286293, 2003, doi: 10.1016/S0921-5107(03)00065-5.

\section{BIOGRAPHIES OF AUTHORS}

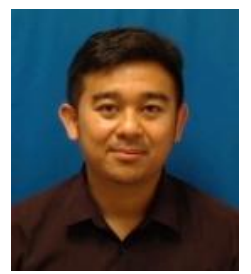

M. I. Idris is an academician from Faculty of Electronic and Computer Engineering, Universiti Teknikal Malaysia Melaka, Malaysia. His research interest is in broadly areas of microelectronic such as MOSFET, diode and solar cell and IC design.

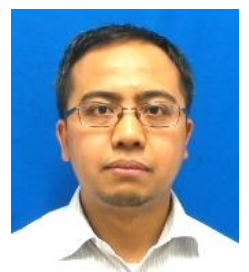

Z. A. F. M. Napiah received the B.Eng. degree in electrical-electronics engineering and the M.Eng. degree in Microelectronic from Universiti Teknologi Malaysia (UTM). He received the Ph.D. degree in Optoelectronics from Kanazawa University, Japan. He is currently a senior lecturer at Faculty of Electronic and Computer Engineering (FKEKK), UTeM. His research interest includes process and device simulation of MOSFET device, CMOS design and CMOS based Photodetector and Photoreceiver.



Marzaini Rashid is an academician at the School of Physics, Universiti Sains Malaysia, Penang, Malaysia. His research area is in the field of nanostructured semiconductors and quantum dots for optoelectronic applications.

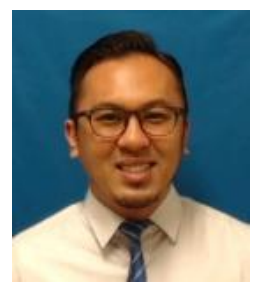

M. N. Shah Zainudin is an academician from Faculty of Electronic and Computer Engineering, Universiti Teknikal Malaysia Melaka, Malaysia. His research interest is in broadly areas of machine learning application, data mining, pattern recognition and smart home. He has published a number of articles related to wide areas of artificial intelligence.

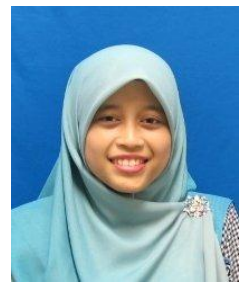

Siti Amaniah Mohd Chachuli is an academician from Faculty of Electronic and Computer Engineering, Universiti Teknikal Malaysia Melaka, Malaysia. Her research interests include metal-oxide semiconductor, thick and thin film fabrication, resistance-based gas sensor and material characterizations.



Mohd Asyadi Azam is an academician from Faculty of Manufacturing Engineering, Universiti Teknikal Malaysia Melaka, Malaysia. His research interests include carbon nanomaterials, 2D materials, energy storage device, corrosion science and engineering. 